- $\quad$ Research in Language 2007, vol. 5

DOI: 10.2478/v10015-007-0001-7

\title{
ARTICLES
}

\author{
Amela Čamdžić, Richard Hudson* \\ University College London
}

\section{SERBO-CROAT CLITICS AND WORD GRAMMAR}

\begin{abstract}
:
Serbo-Croat has a complex system of clitics which raise interesting problems for any theory of the interface between syntax and morphology. After summarising the data we review previous analyses (mostly within the generative tradition), all of which are unsatisfactory in various ways. We then explain how Word Grammar handles clitics: as words whose form is an affix rather than the usual 'word-form'. Like other affixes, clitics need a word to accommodate them, but in the case of clitics this is a special kind of word called a 'hostword'. We present a detailed analysis of Serbo-Croat clitics within this theory, introducing a new distinction between two cases: where the clitics are attached to the verb or auxiliary, and where they are attached to some dependent of the verb.
\end{abstract}

Keywords: clitic, Serbo-Croat, Word Grammar, syntax, morphology, Minimalism, word order, raising.

\section{Overview of the problem}

Serbo-Croat $^{1}$ (henceforth SC) has special clitics, in the sense of Zwicky (1977), which are second-position or Wackernagel's clitics. As a first approximation, let us say that the first position is the one after the first word or the first phrase of the sentence. In (1), (a) and (b) illustrate the placement following the first word (a non-verb and the finite verb, respectively), and (c) the first phrase. Clitics are underlined as in all later examples:

* Authors' address: a_cam_07-ling@yahoo-co.uk; dick@ling.ucl.ac.uk

${ }^{1} \mathrm{We}$ are aware that the old language name "Serbo-Croat", is contentious because some people prefer to distinguish at least three "languages" (Serbian, Croatian and Bosnian). However, we prefer it to any of the alternatives partly because it is the name used by many of the linguists whose work we discuss in this paper, and partly because as far as we know the data we discuss are shared by the standard dialects of all three. Our choice of name has no political implications. 
(1) a. Juče sam joj ih dao. yesterday am to-her it given

'Yesterday I gave it to her.'

b. Dolazite li često ovamo? (Spencer 1991:354)

you-come $\underline{\bar{Q}}$ often here

'Do you come here often?'

b. Prije dva dana sam joj ih dao.

before two day am to-her it given

'I gave it to her two days ago.'

The set of syntactic clitics comprises pronominal and auxiliary elements, as well as the reflexive clitic se together with the question particle li. (SC also has clitic prepositions which are clitics in the phonological sense. They are stress-less and require prosodically strong material for support. However, they do not cluster in the second position and do not belong to the set of syntactic clitics with which we are concerned.)

When a clause contains more than one of these syntactic clitics in a clause, they are positioned together in a cluster which cannot be broken. The ordering within the cluster is fixed and as given below.

(2) li - aux - dat - acc - se - je (or je-se)

Notice the variability in the ordering of the reflexive se and the third person singular auxiliary je. Also, notice the split in the positioning of $j e$ and the other auxiliary forms. While $j e$ is found at the end of the cluster, other auxiliary forms are placed immediately after the question particle $l i$.

\subsection{Second position}

The clitic cluster allows only one constituent to precede it; in other words, it occurs 'in second position' within the clause ${ }^{2}$. As noted above, the preceding constituent may be either the first word of the clause as in $(1 \mathrm{a}, \mathrm{b})$ or the first phrase as in (1c). If we label this constituent ' $\mathrm{X}$ ' (where ' $\mathrm{X}$ ' is either a word or a phrase) and enclose it in square brackets, the placement facts may be stated as in (3).

\footnotetext{
${ }^{2}$ There is an issue here which we shall discuss later, in section 2 of the paper. It concerns the correct characterisation of the domain of cliticisation, i.e. what is the domain relative to which SC clitics have to be in the second position. There are at least two possibilities: the domain is a syntactic entity - a clause - or the domain is prosodic - an intonational phrase.
} 
(3) a. $[\mathrm{X}]-$ clitics $-\ldots$

b. *clitics - ...

c. $*[\mathrm{X} 1]-[\mathrm{X} 2]-$ clitics $\ldots$

In these schemas, (a) is a schematic representation of (1), and (b) rules out clause initial placement as in (4); more generally, SC clitics are enclitics, requiring a host to their left. ${ }^{3}$ Schema (c) excludes the third position shown in (5).

(4) *Je poljubio svoju baku.

Is kissed his grandmother.

'Ivan has kissed his grandmother.'

(5) *[Ivan $]_{\mathrm{X} 1}$ [poljubio $]_{\mathrm{X} 2}$ je svoju baku.

$[\text { Ivan }]_{\mathrm{X} 1}[\text { kissed }]_{\mathrm{X} 2}$ is his grandmother.

To be more precise, (5) fails if it is pronounced under neutral sentence intonation, but separating the subject from the rest of the sentence by an intonational break makes the sentence well-formed. Thus, (6) with an intonational boundary signalled by $/ /$, is well-formed. (As we shall suggest below, this effect of intonation is to be expected if intonation units correspond to units of planning.)

(6) $[\text { Ivan }]_{\mathrm{X} 1} / /$ [poljubio $]_{\mathrm{X} 2}$ je svoju baku.

$[\text { Ivan }]_{\mathrm{X} 1} \quad[\text { kissed }]_{\mathrm{X} 2}$ is his grandmother.

The initial X can be an entire clause-constituent, which may of course consist of a single word or a long phrase as in (7).

(7) Slon sa velikim ušima je spavao pored rijeke.

elephant with big ears is slept by river.

'An elephant with big ears slept by the river.'

However, it may also be merely the first word in a longer clause-constituent, as in (8).

(8) Moj je brat poljubio svoju baku.

my-nom is brother-nom kissed his grandmother

'My brother kissed his grandmother.'

\footnotetext{
${ }^{3}$ There are some exceptions to this rule, like the positioning of the third person auxiliary clitic je. In yes/no questions, je can be placed sentence initially and the result is well formed.
} 
The possessive moj is just part of the subject DP and yet the clitics attach to it.

In general, the order of elements within the clause is extremely free. For example, all three orders of subject, verb and object are possible as in (9).

(9) a. Ivan voli slatki čaj.

'Ivan likes sweet tea.'

b. Voli Ivan slatki čaj.

c. Slatki čaj voli Ivan.

Consequently, the initial $\mathrm{X}$ may have any grammatical function within the clause, so in (10), the initial constituent is a direct object phrase in (a), and a temporal adjunct in (b).

(10) a. $[\text { Svoju baku }]_{X}$ je Ivan poljubio.

[His grandmother $]_{X}$ is Ivan kissed

c. [Prije dva dana $]_{X}$ je stigao u Ediburg.

[before two days $]_{X}$ is arrived in Edinburgh

'He arrived in Edinburgh two days ago.'

In contrast, the order of elements within phrases is more or less rigidly fixed, with some elements obligatorily preceding the head and others obligatorily following it. For example, in the phrases svoju baku, 'his grandmother', and prije dva dana, 'two days ago', the order shown is the only possible one; consequently, the dependent parts of a phrase fall into two categories: those that precede the head and those that follow the head. In contrast, no such distinction applies to the parts of a clause (with one important exception). This difference between clauses and phrases will play an important part in our treatment of clitic-placement.

\subsection{Clitics attached to a participle: "Long Head Movement"}

Even more strikingly, $\mathrm{X}$ may be merely the lexical verb without any other part of the verb phrase, as in (11).

(11) $[\text { Poljubio }]_{\mathrm{X}}$ je Ivan svoju baku.

$[\text { Kissed }]_{X}$ is Ivan his grandmother

'Ivan kissed his grandmother.'

This is surprising if we think in terms of clause constituents moving to the front of the clause because the verb on its own is not a complete constituent. 
However, it is easier to understand if we think of the clitic taking its position from the verb, given the latter's crucial role in the clause. We shall develop this analysis below.

Another surprising fact is that, although a clitic auxiliary freely follows the lexical verb, this is not possible for a non-clitic auxiliary; so we cannot replace the clitic je in (11) with its non-clitic equivalent jeste:

(12) *[Poljubio $]_{\mathrm{X}}$ jeste Ivan svoju baku.

$[\text { Kissed }]_{X}$ is Ivan his grandmother

This is especially surprising in view of the general freedom of order within the clause discussed above. If poljubio in (12) depends on jeste, as we assume it does, then it might be expected to have the same freedom of position as other dependents; but it does not. Rather, the order of (non-clitic) auxiliaries and their dependent participles is as rigidly fixed as the order of parts within a phrase.

Equally surprisingly, although clitics generally attach freely to entire phrases (as we have already seen in (7), for example), this freedom does not extend to VPs so (13) is not possible.

(13) *[Poljubio svoju baku $]_{\mathrm{X}}$ je.

[Kissed his grandmother $]_{\mathrm{X}}$ is.

'He kissed his grandmother.'

The fact that the participle must be separated from its dependents as in (11) is a challenge for any theory, as it illustrates the much discussed phenomenon of so-called Long Head Movement (Ackema, Čamdžić 2003, Bošković 1995, 2001, Rivero 1991, 2001, Roberts 1993, Wilder, Cavar 1993, 1994, Williams 2003, etc.).

The traditional generative understanding of Long Head Movement, exemplified by works such as Rivero $(1991,2001)$ and Roberts (1993), is as follows: The participle originates within the VP. It moves from its base position, across one (or more) auxiliary clitics. The participle is an $\mathrm{X}^{0}$ category, as are the auxiliaries it crosses. Its movement creates the representation in (14), which represents a violation of minimality conditions.

(14) Poljubio $_{1}$ je $t_{1}$ svoju baku

$\left[\begin{array}{lllllll}X_{1}^{0} & \ldots & Y^{0} & \ldots & t_{1} & \ldots\end{array}\right]$

kissed $_{1}$ is $\quad \mathrm{t}_{1}$ his grandmother

The claim that Long Head Movement involves a genuine violation of locality conditions is supported by several properties of the construction, such as the 
impossibility of VP fronting in the same environment (13) and the blocking effect of negation (15).

(15) *Poljubio nije svoju baku.

kissed didn't his grandmother

'He didn't kiss his grandmother.'

The reasoning is that if LHM was an instance of phrasal (remnant) displacement, then full VP fronting would also be possible. Example (13) shows this not to be the case, ${ }^{4}$ so the participle fronting must be an instance of head movement. The blocking effect of negation, on the other hand, is explained by the fact that the negation is a head, and thus, by minimality exerts a blocking effect on the fronting of the participle.

The data in (13)-(15) are often taken as an argument for the modification of the minimality constraints governing the displacement of heads. Perhaps the most influential analysis is due to Roberts (1993), who argues that head movement parallels phrasal movement in that it is relativized to the type of the intervener. Phrasal A-movement is blocked by A-interveners, and A'movement by $\mathrm{A}^{\prime}$-interveners. A-elements do not interfere with $\mathrm{A}^{\prime}$-movement. Roberts argues that the same holds for heads. The participle movement is an instance of A'-movement, while the auxiliary is an A-head. Thus, the movement is well formed. Similarly, the negation is an $A^{\prime}$-intervener, and therefore it blocks the fronting of the participle in (15).

Our analysis will follow very different lines. As suggested earlier, we believe that it is the clitic je rather than the participle that 'moves' (in the sense of taking a special position). However, other pre-clitic elements are indeed 'moved' to the front of the clause, but this is not possible for the VP because of the special (and exceptional) ordering of auxiliary and participle seen in (12). We shall explain our analysis in more detail below.

\subsection{Clitics in embedded and coordinated clauses; clitic climbing}

The data above describe the simplest cases of clitic positioning in main clauses. We now consider cases where the clause starts with a 'conjunction', a term that we shall use for simplicity to cover complementizers, coordinating conjunctions and clausal prepositions. In embedded and coordinated clauses, the clitic cluster generally preserves its second position, now immediately following the conjunction as in (16).

\footnotetext{
${ }^{4}$ It needs to be mentioned that VP fronting across clitics is possible for some speakers as reported by Wilder, Cavar (1994a).
} 
(16) ... da je Ivan poljubio svoju baku.

that is Ivan kissed his grandmother

'... that Ivan has kissed his grandmother.'

No other element is allowed between the conjunction and the clitic, as in $(17){ }^{5}$

(17) *da Ivan je poljubio svoju baku.

that Ivan is kissed his grandmother

However, certain conjunctions - for example, $i$ ('and') - never host the clitic cluster, so some other element stands before the clitic as in (18) and (19).

(18) Marija je ubrala cvijeće i Ivana ga stavila u vazu.

Maria is picked-up flower, and Ivana it put-part in vase.

'Maria has picked up a flower and Ivana has put it in the vase.'

(19) *Marija je ubrala cvijeće i ga Ivana stavila u vazu.

Maria is picked-up flower, and it Ivana put-part in vase.

'Maria has picked up a flower and Ivana has put it in the vase.'

In contrast, both possibilities are allowed with other conjunctions such as jer ('because') in (20) and (21), from Radanowič-Kocić (1996).

(20) Raduj se, jer došao ti je brat.

Be-happy $\underline{\text { se}}$, because come-part to-you is brother.

'Be happy because your brother has arrived.'

(21) Došao je jer je saznao da si tu.

Come-part is because is found-out that you-are there.

'He came because he has found out that you are here.'

Clitic climbing is possible out of the complements of certain verbs (mostly the verbs of volition). It is obligatory when the complement is an infinitival form and marginally possible when the complement is a $d a$ clause.

(22) Ivan ga je htjeo vidjeti.

Ivan $\underline{\text { him }} \underline{\text { is }}$ wanted see

'Ivan wanted to see him.'

\footnotetext{
${ }^{5}$ Apparently sentences such as (17) may be possible for some speakers. We have seen this claim in a paper by Pogrovac which we can no longer trace.
} 
(23) Ivan ga je htjeo da vidi.

Ivan him is wanted that sees.

'Ivan wanted to see him.'

These two complement patterns are distributed regionally, with infinitives in the west (mainly Croatia) and $d a$ clauses in the east (mainly Serbia).

\subsection{Delayed placement}

Delayed placement allows the clitic to be placed in a position later than the second. One such example was given earlier as (6), where $\mathrm{X}$ follows another phrase separated from the rest of the clause by a prosodic boundary. A further example is (24).

(24) [Veliki sivi slon $]_{\mathrm{X} 1} \quad\left[\right.$ spavao $_{\mathrm{X} 2}$ je pored rijeke.

[Big grey elephant $]_{\mathrm{X} 1}[\mathrm{slept}]_{\mathrm{X} 2}$ is by river

'A big grey elephant slept by the river.'

Like (6), this example seems to require some kind of prosodic break between the two bracketed strings, though this may be less noticeable after a multi-word phrase (as here) than in single-word examples like (6).

The delayed placement is actually optional since it is possible to attach the clitics to the end of a multi-word phrase like the one in the last example, giving (25).

(25) [Veliki sivi slon $]_{X}$ je spavao pored rijeke.

[Big grey elephant $]_{X}$ is slept by river.

'A big grey elephant slept by the river.'

However, the longer the initial constituent, the more likely the delayed placement. Thus, the very long initial phrase in (26) is very unlikely to be a clitic host and the tendency for the delayed placement of clitics is very high.

(26) $[\text { Cirkuski sivi slon sa velikim ušima }]_{\mathrm{X} 1}\left[\right.$ spavao $_{\mathrm{X} 2}$ je pored rijeke.

[Circus grey elephant with big ears $]_{\mathrm{X} 1} \quad[\mathrm{slept}]_{\mathrm{X} 2}$ is by river

'A big grey circus elephant with big ears slept by the river.'

Such examples show that the 'second-position' generalisation is only a first approximation to a more complex reality which includes delayed placement. 
Indeed according to Bennett (2002), delayed placement is common in SC. A further example of delayed clitic placement is given in (27), where the clitic is pushed to a later position by the intervening appositive phrase, a constituent characterized by parenthetical intonation.

(27) Ja, tvoja mama, kupiču ti sladoled. Radanović-Kocić (1996) I-nom, your mother, buy-will to you ice-cream.

'I, your mother, will buy you an ice-cream.'

As example (28) illustrates, the same pattern is possible in embedded clauses.

(28) Mislim da, kao što smo već rekli, Ivan će svirati Think-I that, as we-are already said, Ivan will play na sutrašnjem koncertu. on tomorrow's concert.

'I think, that as we have already said, Ivan will play in tomorrow's concert.'

In general, then, it seems that the clitic and its host may in fact follow a considerable amount of material from the same clause, provided that this is sufficiently distinct in terms of prosody and/or complexity. This 'preliminary material' must be accounted for in any analysis, and will play an important part in ours.

\subsection{Split clusters}

Finally, we must recognize a marginally possible pattern, discussed by Bošković (2000), where the clitic cluster is split as in (29), from Wilder and Čavar (1997), quoted in Bošković (2001: 51).

(29) Oni su // kao sto sam vam rekla // predstavili se Petru.

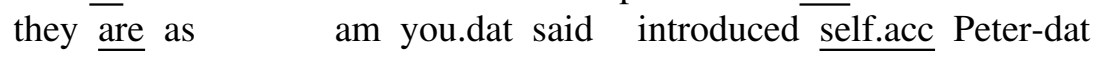
'They, as I told you, introduced themselves to Peter.'

Examples like (29) raise special issues which we discuss in section 7 of this paper.

This survey has ranged widely over the patterns of cliticization found in $\mathrm{SC}$, and the WG analysis that we shall present below will cover most of the facts mentioned here. We shall draw attention to the gaps which are inevitable given the space available here. 


\section{Previous analyses}

SC clitics have been a subject of vigorous research over the years, and consequently, the literature on the subject is extensive (Bennett 1987, 2002; Boeckx, Stjepanović 2000; Bošković 1995, 2000, 2001; Caink 1998; Franks 1997; Halpern 1995; Progovac 1996, 2000; Radanović-Kocić 1996; Rivero 1993, 1997; Roberts 1992; Schütze 1994; Stjepanović 1998; Tomić 1996; Wilder, Cavar 1994a, 1994b; Zec, Inkelas 1990 etc).

There are a great many analyses because SC "is increasingly becoming a testing ground for theories of second position cliticization. As a result, the argumentation and the kind of data examined with respect to second position cliticization in SC have reached a level of subtlety not attested in the discussion of the phenomenon in other languages." (Bošković 2001: 8)

The most extensively discussed issue of SC cliticization in the GB/Minimalist literature is what role phonology plays in explaining the "second position" (P2) of clitics. On this basis we can divide the analyses roughly into three groups:

- those which maintain that P2 is entirely a syntactic phenomenon, as is, for instance, maintained by Franks (1997), Progovac (1996, 2000), Rivero (1997), Roberts (1994), Tomić (2000), Wilder and Cavar (1994a and 1994b), etc.,

- those that claim that P2 is entirely a phonological phenomenon as in Caink (1998), Radanović-Kocić (1996),

- those which argue that both syntax and phonology play a role in deriving the P2 effect: Halpern (1995), Schütze (1994), Bošković (2000, 2001), etc.

It is beyond the scope of this paper to present and discuss all the work done on SC clitics so far. Rather, we shall restrict ourselves to three particular accounts, namely those proposed by Progovac (1996), Schütze (1994) and Bošković (2001) and provide a very brief overview of these.

\subsection{Progovac (1996)}

Progovac's analysis of P2 cliticization parallels the classical analysis of V2 phenomena. The basic claim is that in all constructions clitics are found in a unique structural position, identified as the head of CP to which the clitics right-adjoin (Figure 1). The preceding material is either brought forward to Spec C by a variety of syntactic movements (topicalization, wh-movement, etc.) or it is the complementizer (e.g. $d a$ ) in embedded clauses. 


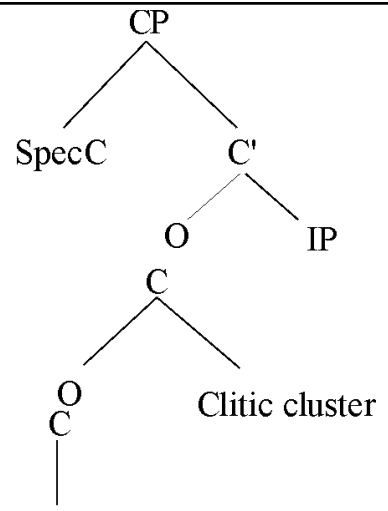

(da)

Fig. 1. Clitic clusters adjoin to the head of $\mathrm{CP}$

The main tenet of this analysis is the claim that the domain of cliticization is a clause, and that second position is entirely derived by syntactic means. For example, consider how this analysis would apply to (1a) repeated here:

(30) Juče sam joj ih dao. yesterday $\overline{\mathrm{am}}$ to-her it given

'Yesterday I gave it to her.'

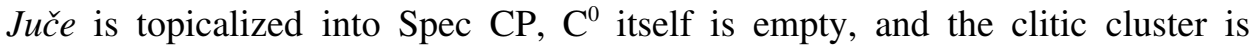
adjoined to $\mathrm{C}^{0}$, leaving dao in IP.

The analysis by Progovac treats P2 in main clauses just like V2, in which the finite verb is placed after a single extracted element. The analysis unifies two apparently distinct phenomena, which is a benefit if they really are the same, but it has serious weaknesses. Here we list those which we consider the most important:

- It does not explain the special relation between the extracted material and an overt complementizer, whereby exactly one of them is obligatory; this must be handled by a filter such as the 'Doubly-filled Comp Filter', which is an arbitrary stipulation that detracts from the structural explanation (albeit a stipulation which is needed for other constructions).

- It does not explain why a participle can be fronted on its own as in (11), repeated below as (31). As mentioned earlier, it is impossible to front the entire VP, which is strange if fronting is due to extraction; and examples like (31) also involve Long Head Movement, contrary to the Head Movement Constraint.

(31) $[\text { Poljubio }]_{\mathrm{X}}$ je Ivan svoju baku. 
[kissed] is Ivan his grandmother

'Ivan kissed his grandmother.'

- It does not explain why the pronominal clitics move to $\mathrm{C}$, or why they cluster.

- It does not explain the delayed placement discussed in 1.4; even if the 'preliminary material' is adjoined to $\mathrm{CP}$, the strong pressure for prosodic distinctness remains to be explained.

\subsection{Schütze (1994)}

The mixed syntactic and phonological account increases the number of possible derivations by admitting the possibility of manipulating linear order by mechanisms which do not fall within the domain of syntax proper.

Schütze (1994) argues for the following proposal. All constructions which are arguably built by well-formed syntactic rules are derived in syntax. In this respect, Schütze's proposal is exactly like Progovac's i.e. the clitics cluster under $\mathrm{C}^{0}$ and are preceded by the fronted material. However, when a sentence is acceptable but there is a reason to believe that strictly syntactic rules have been violated, such constructions must have been derived in a different module of the grammar, namely phonology. Phonology allows for changes in the linear order of syntactic elements by at least one operation - so-called Prosodic Inversion (PI). The PI analysis was first developed by Halpern (1995) and later modified by Schütze (1994). We choose to discuss the version of the proposal as developed by the latter since it is closer to Progovac and thus makes the comparison easier.

The rule of PI operates at the post-syntactic level (i.e. at the phonological level of representation) and is triggered by the phonological properties of clitics - namely, the need for a phonological host. It moves the clitic cluster to the right, across the first prosodically well formed lexical item. PI is only triggered when the output of the syntactic derivation is such that no phonological host is provided and as such it is really a sort of a repair mechanism.

One of the most convincing cases of a construction which would have to be derived by PI is the placement of clitics such that they split proper names. An example of this is given below in (32):

(32) Lav je Tolstoj autor Ane Karenjine.

Leo-nom is Tolstoy-nom author Ana-gen Karenina-gen

'Leo Tolsotoy is the author of Ana Karenina.' 
Superficially similar patterns, with clitics splitting up syntactic phrases, can be widely observed in SC. An example of it was given in (8), which is here repeated as (33).

(33) Moj je brat poljubio svoju baku.

My is brother kissed his grandmother

'My brother has kissed his grandmother.'

However, it has been established that when such patterns are possible, they are derived syntactically, by left branch extraction. Thus, not only clitic material may split the phrase, but also non-clitic material, as in (34).

(34) Moj je poljubio brat svoju baku.

my is kissed brother his grandmother

Going back to (32), proper names are islands and left branch extraction out of them is generally considered impossible. Therefore, the sentences such as this cannot be derived in syntax. On this analysis they are derived by PI. The derivation of (32) is given in (35). The (a) structure is the output of syntax and input into PI. The (b) structure is the output of PI.

(35) a. je Lav Tolstoy autor Ane Karenjine.

Leo Tolstoy author (of) Ana Karenina

b. Lav je Tolstoy author Ane Karenjine.

Leo is Tolstoy author (of) Ana Karenina

PI thus saves clitic-initial sentences by repairing them in phonology. This solves the problem of split proper names by removing it from syntax, and also explains a further interesting set of data in which a clitic apparently occurs inside a fronted PP:

(36) a. U ovu je veliku sobu usao.

In this is big room entered.

'He entered into this big room.'

b. je u ovu velliku sobu usao.

in this big room entered

On PI analysis, (a) in (36) is derived from an underlying structure in which the auxiliary clitic je is initial, as in (b). In this example the first word after the supposedly initial clitic $j e$ is a preposition, which is itself a proclitic, so it is not a suitable host for the other clitic; this therefore moves after the next word in spite of the grammatical phrase boundaries. 
However for all its apparent success in these two cases, Schütze's analysis has a number of serious weaknesses:

- The analysis increases the possibilities of clitic placement that the grammar permits. In particular, the grammar predicts that any phonologically strong element is capable of hosting the clitic cluster. As noted before (Wilder, Cavar 1994a; Progovac 1996; Bošković 2001), even in clause-initial position this is not always true. For example, SC has a set of prepositions which may be either phonological clitics or phonologically strong, but even the phonologically strong preposition cannot act as host to a clitic:

*Prema su Mileni Milan i Jovan isli. (Bošković 2001: 14) towards are Milena-dat Milan-nom and Jovan-nom walked. 'Milan and Jovan walked towards Milena.'

- A fortiori, the analysis does not explain why multiple clitics cluster together.

- The explanation for examples like (32) is redundant since a more detailed investigation of SC syntax reveals that such examples are derived in syntax (cf. Bošković 2001).

- The explanation for examples like (36) is redundant if (as claimed by Bošković 2001: 20) a preposition phrase can be split in the same way by non-clitics. Here are Bošković's examples, in which the intervener is the personal pronoun on (he) and Jovan which do not belong to the set of second position clitics.

(38) a. (?)U ovu on veliku sobu ulazi.

In this he big room enters

'He enters into this big room.'

b. ??U ovu Jovan veliku sobu ulazi.

In this Jovan big room enters

'Jovan enters into this big room.'

In short, there is no need for the phonological sledge-hammer of Prosodic Inversion in order to crack what is basically a syntactic nut.

\subsection{Bošković (2001)}

Finally, we discuss the proposal by Bošković (2001). Bošković argues for an analysis in which both syntax and phonology play a role in cliticization. Syntax provides a range of possible structural positions in which clitics can be found, while phonology determines their spell-out position. 
Bošković's proposal rests on several major assumptions. Firstly, he argues that the domain of cliticisation is an intonational phrase (IP). Clitics have to be found in the second position relative to this prosodic constituent. This requirement, which acts as a phonological filter, is more formally given as follows:

1. suffix

2. \#

Bošković (2001: 83)

The first clause of (39) states that clitics are suffixes i.e. they follow their host. The second clause contradicts the first one. It states that clitics have to be placed adjacent to a prosodic boundary. This clause on its own would force the initial placement of clitics, the possibility ruled out by the first clause. The conflict between these two opposing constraints is resolved by second position placement. For this to work, a version of Marantz's Morphological Merger $(1988,1989)$ needs to be assumed. In Bošković's version this reads as follows:

\section{(40) Morphological Merger}

At any level of analysis, independent constituents $\mathrm{X}$ and $\mathrm{Y}$ standing in a relation at that level (or heading phrases standing in that relation) may merge into a single word $\mathrm{X}+\mathrm{Y}$, projecting the relation between (the constituent headed by) $\mathrm{X}$ and (the constituent headed by) $\mathrm{Y}$ onto the affixation relation $\mathrm{X}+\mathrm{Y}$. (Bošković 2001: 84)

A second assumption on which Bošković's proposal is based exploits the possibilities which arise out of the copy theory of movement (Chomsky 1993). On this view, the displaced syntactic element leaves an exact copy in its base position, as well as any intermediate positions through which it moves. It is generally assumed that the spell out process targets the head of the chain. However, Bošković together with other authors (Bobaljik 1995, Franks 1998, Nunes 1999, Roberts 1997, etc.) argues that a spelled out copy need not be the head of the chain. Indeed, on his account, the copy of clitic elements which is spelled out in phonology is the one that stands in the second position as required by (39).

Let us consider how this works on a concrete example. Pronominal dative and accusative clitics are base generated in the direct and indirect object positions respectively. From there, they move to their agreement positions in order to check case and agreement features. This creates the following configuration: 
(41) ...[AgrIOP dative clitic [AgrIOP accusative clitic [VP ... accusative clitic dative clitic]]]

Copies of pronominal clitics are present at the foot of the chain i.e. within $\mathrm{VP}$, and in the head of the chain i.e. in agreement positions. The standard understanding of grammar would have it that at spell out, the upper copies are phonetically realised and the lower copies deleted.

In a similar fashion, clitic auxiliaries are initially merged in a low position - AuxP - from which they undergo head movement up to AgrS, leaving behind a series of copies, as in (42).

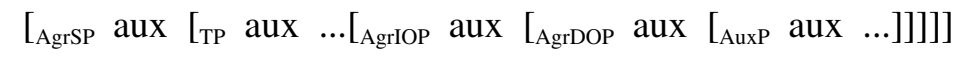

Which one of these copies is spelled out again depends on (39). Consider the following two examples:
a. Ivana je napravila kolače.
Ivana-nom is made cakes
'Ivana has made some cakes.'
b. Napravila je kolače.
'She has made some cakes.'

The sentence in (a) has the structure given in (44), where the subject is in the specifier of AgrSP and the clitic auxiliary is present in all the head positions beginning with AuxP.

\section{(44) [AgrSP Ivana [AgrSO je [TP vjerovatno [T0 je [AuxP je ....]]]]}

We can disregard the positioning of other syntactic elements other than the sentential adverb which Bošković considers to be adjoined to TP. Now, by (39) the copy of the auxiliary that has to be spelled out is the highest one, i.e. the one in $\operatorname{AgrS}^{0}$ since it is the only copy that satisfies the phonological filter. Any lower copy puts the clitic auxiliary in a position lower than the second, and this is ruled out.

In (b) of (43), on the other hand, the clitic has to be spelled out in a lower position than in (44), for the simple reason that the highest host available is present in a lower position. This position is the head position of PartP (participial phrase), which dominates the agreement position, and is dominated by a higher TP and AgrSP. The underlying structure of (b) is given in (45). 
(45) $\left[\right.$ AgrSP $\left[\operatorname{AgrS}^{0}\right.$ je $\left[\mathrm{TP}\left[\mathrm{T}^{0}\right.\right.$ je $\left[\mathrm{PartP}\left[\mathrm{PartP}^{0}\right.\right.$ napravila je $[$ AuxP je ....]]]]

The phonological conditions would force the spell out in (45) of the auxiliary clitic in the head of PartP. Any higher spell out would leave the clitic without a host.

Bošković further argues that the domain of cliticization is an intonational phrase rather than the syntactic clause. The argument for this position is the delayed placement of the clitic cluster in the presence of parentheticals. Consider the following:

(46) a. *Ja // tvoja mama // sam ti obećala sladoled.

I your mother am to-you promised ice-cream.

'I, your mother, promised you an ice cream.'

b. Ja // tvoja mama // obecala sam ti sladoled.

I your mother promised aux to-you ice-cream

'I, your mother, promised you an ice cream.'

The presence of the intonation boundaries which offset the appositive in the example above is what causes the clitic to be spelled out in a lower position then the second position of the clause. Assuming that the position of the subject is not different in this example from its position in the equivalent sentence without the appositive, it follows that the second position is correctly defined as the second position of the Intonational Phrase, rather than the second position of the clause.

Clitics attached to $d a$ (that) as in (16) and to jer in (21) (repeated below) may be a problem for this analysis, because it can only allow them when $d a$ follows an intonation boundary.

(47) ...da je Ivan poljubio svoju baku.

that is Ivan kissed his grandmother

'... that Ivan has forgotten his grandmother'
Došao
je jer
je saznao da si tu.

Come-part is because is found-out that are there.

'He came because he has found out that you are here.'

Admittedly, standard assumptions recognize an IP boundary before $d a$, and associate IP boundaries with intonation boundaries; but there is very little empirical evidence for such boundaries in SC. Even if intonation boundaries are possible before $d a$, it seems extremely unlikely that they are any more 
obligatory in SC than in English sentences such as I think that it's going to rain. But if they are optional we should expect a linkage between clitic placement and intonation whereby clitics are only attached to $d a$ when this follows an intonation boundary. So far as we know, nobody has suggested that this is the case.

In conclusion, the previous analyses have already established a number of important descriptive facts about SC clitics (which we listed in section 1), and have highlighted the dual role of clitics as syntactic elements with the special "phonological" property of needing an immediately adjacent host to "lean"' on. Bošković's analysis has the added virtue of relating clitics explicitly to suffixes. However the analyses suggested also have serious weaknesses, so there is clearly room for alternative approaches. One kind of alternative that has already been offered for slavic clitics has rested on the ideas of Optimality Theory (e.g. Anderson 1996, Legendre 1999). However the analysis that we propose below is radically different from all the previous analyses and (we believe) avoids their weaknesses - though we shall admit the gaps that we are aware of.

\section{Towards a Word Grammar analysis of SC clitics}

At the heart of the WG analysis is the rather obvious idea that in syntax clitics are ordinary words but they are realised morphologically by mere affixes. Like other affixes, their position is determined by the rules of morphology, and they behave phonologically like word-parts. But like other words, they have regular syntactic dependency relations to the rest of the sentence and typically carry separate referents. Let us start with our very first example (1):

(49) Juče $\frac{\text { sam joj }}{\text { yesterday }} \frac{\text { ih dao. }}{\text { am to-her it given }}$
'Yesterday I gave it to her.'

In terms of syntax, there are five words (as shown in the conventional orthography) with ordinary dependencies as shown in Figure 2. (We shall argue below that there is in fact another syntactic word in this sentence: the one consisting of the clitic cluster and its host Juče-sam-joj-ih. For the present we shall ignore this.) 


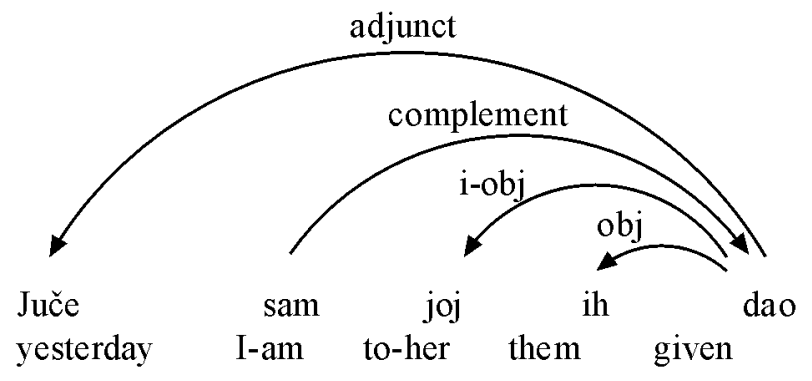

Fig. 2. The syntactic dependencies of Juče-sam-joj-ih dao

In terms of morphology, however, the clitics are realised by affixes, so there are just two complete word-forms (full morphological realisations of a word):

- Juče-sam-joj-ih: this word-form has a typical rigidly fixed morphological structure (stem followed by three suffixes - compare Latin am-ab-a-t-ur 'he/she used to be liked', consisting of the stem am plus four rigidly ordered suffixes); it also carries a single word-stress.

- dao: an ordinary word.

This structure can be shown by adding an extra 'level' to the syntactic network as in Figure 3, with one arrow linking each word to its morphological realisation and another arrow linking single morphemes to the complete word-form of which they are part. The morphemes and word-forms are distinguished from the words by the convention of enclosing them in curly brackets: so the morpheme MsamN is a distinct analytical entity from the word sam. For present purposes the nature of the morphological links can be left undefined but we shall add details later when we explain how (and why) the clitics line up after their host.

In summary, the syntax is not responsible for where the clitics stand but neither is the morphology responsible for selecting the stem and clitics or for deciding which combinations are possible. This is handled by the syntax. The mismatch between syntax and morphology means that clitics are a challenge for any theory of sentence structure. The kind of theory which clitics call for is one in which morphology and syntax are distinct, each following its own set of combinatory principles and rules but with some kind of 'correspondence rules' (Jackendoff 2002) mapping them onto one another. Sadock is probably the best defender of this view (Sadock 1991), but his Autolexical Syntax is not the only such theory. Recent 
versions of WG have also adopted the same distinction between syntactic words and morphological 'forms' (including complex word-forms). Hudson (2001) is a general discussion of clitics with detailed application to French and tentative speculation about SC; however, the present theory of clitics is presented in the context of a general theory of language structure in Hudson (2007).

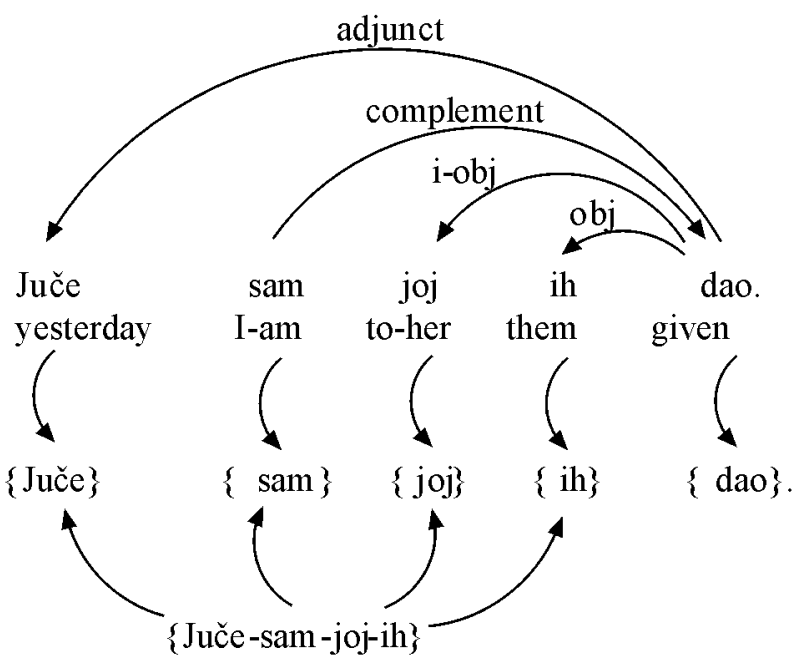

Fig. 3. The syntactic and morphological structures of Juče sam joj ih dao

What we have just said about the independence of syntax and morphology applies to clitics in any language, but P2 languages such as SC oblige us to push the theory a little further. In these languages, unlike languages such as French, the position of the clitics cannot be derived simply from their ordinary dependency relations plus the morphological ordering. Indeed, the clitic cluster has a special place in clause structure - the "second position" - which is only relevant to clauses that contain clitics. To accommodate P2 languages, therefore, we need a syntactic element to mark the position of the clitics and their host, in addition to the complex word-form in morphology that contains them. We propose to call this element a "hostword", which by definition will be a word whose realisation is the wordform containing all the clitics and their "host'. In addition to this realisation, the hostword carries ordinary syntactic dependencies but has no meaning, so although it is a word it is not a typical one. This extra element is shown, without any further dependencies, in Figure 4. We distinguish it from the separate words by hyphens (which are not, of course, part of ordinary SC orthography). 


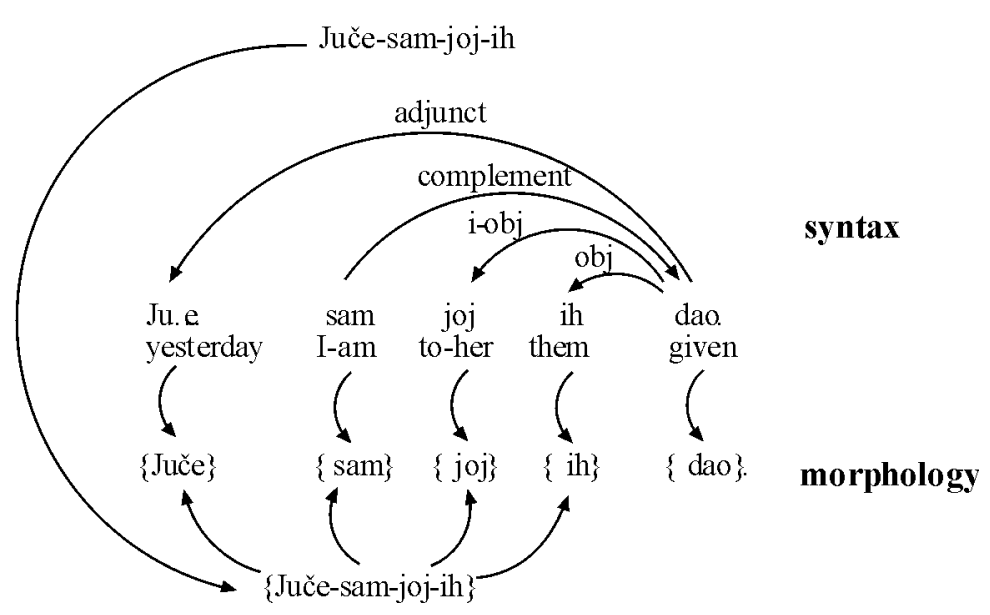

Fig. 4. Structure of Juče sam joj ih dao including the hostword Juče-sam-joj-ih

The hostword's morphological structure is defined by rules just like the other rules of morphology - and it is interesting to notice that SC has quite rich inflectional morphology, so the rules for clitic clusters are not out of place in this language. Indeed, it is intriguing to speculate about a general typological tendency for special clitics to co-occur with rich inflectional morphology; we don't know whether this is generally true, but it does seem to be true of the languages we know about. As we shall see in detail below, this morphological structure explains the relative order of clitics, why they have to follow a host and also why they cluster together.

However, it was in relation to syntactic structure that we justified the hostword. This is why we need a hostword as well as the word-form that realises it. In our analysis, the reason why the hostword occurs in second position is because all the other elements of the clause depend on it and take their position from it (and mostly after it). This makes the hostword pivotal in the structure of the clause, because the clitics also take their position within it. If all the other words or phrases in the sentence depend on the hostword, they can easily be required to follow it by normal word-order rules (whose details need no discussion here). Thus the hostword is clauseinitial, but of course its first part is the host, so the 'second position' of the clitics follows from the morphological fact that they are enclitics, i.e. realised by suffixes (as in Bošković's analysis).

Moreover we can even use the hostword to deal with delayed placement, where 'preliminary material' stands before the hostword as in (24) repeated here: 
(50) Veliki sivi slon spavao je pored rijeke. big grey elephant slept is by river

'A big grey elephant slept by the river.'

In this example the hostword is spavao-je, but it is not clause-initial. What is needed, it seems, is a pre-dependency by virtue of which slon ('elephant') may precede it. This is easily arranged by permitting a hostword optionally to have a dependent before it, which in this case is slon, the head of the initial phrase. It is even possible to exploit this possibility for examples like (51), another possible realisation of the same combination of words as in (50).

(51) Veliki sivi slon je spavao pored rijeke. big grey elephant is slept by river 'A big grey elephant slept by the river.'

In this case, the last word of the preceding phrase doubles as the host inside the hostword. Once again, the details of the analysis will appear below.

When a hostword has a preceding dependent the structure is very similar to the one needed in a dependency analysis of V2 clauses, where it is the finite verb that has a single preceding dependent. Given these similarities, it is not surprising that P2 clitics (so-called Wackernagel clitics) are related historically to V2 patterns, so that languages frequently move from one type to the other. This diachronic pattern has been documented in the Slavic languages by Bennett (1987, 2002), and more generally by Anderson (1993). In both kinds of language a finite auxiliary may be in second position, either by virtue of being finite (V2) or by virtue of being a clitic (P2), so languages can easily slip between the two types by gradually shifting the balance of features between finiteness and clitic-hood.

The hostword, then, is the main idea behind the WG analysis of SC clitics. So far as we know it is original, but of course the general idea that special clitics are subject to morphological constraints as well as syntactic ones is not at all new. In the rest of this paper we shall develop the idea in more detail and with a little more attention to formalisation.

\section{Dependency structures}

In WG, sentence structure is analysed in terms of dependencies between pairs of single words and phrase structure, as such, plays no part. We shall take this general assumption for granted, along with a fairly uncon- 
troversial set of particular dependencies (subject, object and so on) such as those shown in Figure 2. The challenge is to integrate them with the extra relations (morphological and syntactic) needed for the hostword, but we start with a general look at ordinary (non-clitic) word order in SC. We shall see that there is a great deal of syntactic "raising" which makes word order extremely free - a freedom which contrasts even more markedly with the rigid ordering of clitics.

In general, word order within the clause is free, so a verb and its dependents may occur in any of the orders illustrated in (9), repeated here.
a. Ivan voli slatki čaj.
'Ivan likes sweet tea.'
b. Voli Ivan slatki čaj.
c. Slatki čaj voli Ivan.

Free order is handled in WG simply by having no word-order rules - i.e. no default or overriding word-order rules, in contrast with languages like English.

However SC clause order is even free-er than this, because it allows apparent phrases to be split; for example, the phrase slatki čaj, 'sweet tea' can be split by the verb or other dependents of the verb:
(53) a. Slatki Ivan voli čaj.
b. Ivan slatki voli čaj.
c. čaj Ivan voli slatki.
d. ??čaj Ivan slatki voli.

The easiest way to explain this pattern is to allow slatki to depend directly on the verb as well as on $\check{c} a j$. This is just like the "raising" that we recognize in subject-sharing, extraction or extraposition, whereby a dependent of one word also depends on this word's parent. If slatki depends on voli, "likes", then it can move freely around this word regardless of where its other parent is. The result of raising is a structure like Figure 5 in which " $x$ " is the label for the raising dependency and may be thought of as short for "extra", and as reminiscent of both "extractee" and "extraposee". In this diagram and later ones, we follow the WG practice of drawing any dependency arrows which would cross other arrows below the words; a general principle means that a grammatical sentence always has a complete dependency structure above the words. 


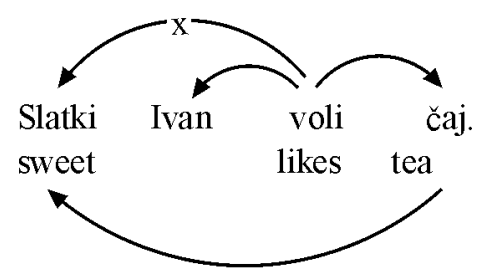

Fig. 5. A raised syntactic dependency

Not every phrasal constituent can be raised in this way, but before we explain the limits of raising we must explore the word-order rules for nonraised phrase constituents. As mentioned earlier, the order of words within phrases is fixed at least to the extent that each kind of dependent is quite rigidly located either before or after the head of the phrase - for example, a noun's determiners and adjectives always precede it, whereas its modifying prepositional phrases and relative clauses always follow it; and a preposition's complement always follows it (unless the preposition is a clitic - a type of clitic which we are ignoring in this paper). This strict division of dependencies into two types according to whether the dependent precedes or follows the head is also found in languages like English, though in English it also applies in clause structure. In the WG analysis of English, the distinction is handled by means of a high-level distinction between "pre-dependents", which precede the head, and "postdependents", which follow it (Hudson 1990: 189). Pre-dependents are further distinguished in terms of categories such as subject and pre-adjunct, while post-dependents include most complements and "post-adjuncts". We propose to apply a similar classification to SC, but because most elements of clause structure can move freely around the head verb, we shall exclude dependencies such as subject and object from the distinction between pre-dependent and post-dependent. A schematic version of this classification of dependents is shown in Figure 6.

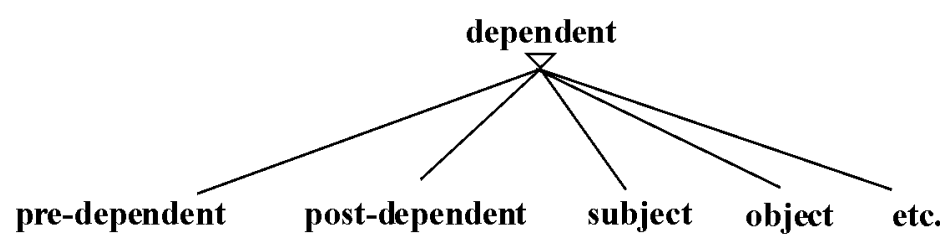

Fig. 6. A preliminary classification of SC dependencies

It is important to stress that the distinction between pre-dependent and post-dependent is not merely a classification of surface positions. For example, not every dependent that precedes its head is a pre-dependent, but only those which (normally) have to precede their heads. A noun's 
determiner is its pre-dependent, but a verb's subject is never its pre-dependent regardless of whether it stands before or after the verb. Moreover, at least in English a pre-dependent can, exceptionally, follow the head; for example, an auxiliary verb's inverted subject (as in Are you ready?) is still its predependent (and has some of the characteristics of pre-dependents such as resistance to extraction).

The distinction between pre- and post-dependent is helpful in at least two areas of SC grammar relevant to our present concerns. First we may apply it to the 'raising' which allows a modifier such as slatki (sweet) to be separated from the head noun such as $\check{c} a j$ (tea). As we mentioned earlier, this raising is possible for some dependents but not for all. For example, an adjective may be separated from the noun it modifies as in (53) above, and the same is possible for a determiner or a given name as in (32) and (33), repeated below:

(54) Lav je Tolstoj autor Ane Karenjine.

Leo-nom is Tolstoy-nom author Ana-gen Karenina-gen

'Leo Tolstoy is the author of Ana Karenina.'

(55) Moj je brat poljubio svoju baku.

My is brother kissed his grandmother

'My brother has kissed his grandmother.'

We assume that all these separated words are pre-dependents of the noun. But separation is not possible for a prepositional phrase.

(56) a. Ivan vidi čovjeka [u crnom šeširu].

Ivan sees man [in black hat]

'Ivan sees a man in a black hat.'

b. *[U crnom šeširu] Ivan vidi čovjeka.

c. *čovjeka Ivan vidi [u crnom šeširu].

Nor can a preposition be separated from its own complement:

(57) a. Ide prema kući.

he-goes towards house

'He goes towards the house.'

b. *Prema ide kuči.

In both these cases the inseparable item is the post-dependent of the head-word from which it cannot be separated. From these and other examples we conclude that separation is possible only for pre-dependents, so only predependents can be raised to attach to the verb. 
This distinction is also helpful in understanding the restrictions on auxiliary verbs. On the one hand, auxiliaries and auxiliary-like verbs such as 'want' extend the flexibility even further by allowing raising in "clause union'. In such cases, the complement's own dependents are free to move around within the main clause as though they depended on the main verb directly - as indeed they do, according to the proposed analysis. For example:

(58) a. Želim pojesti jabuke.

I-want eat apples

'I want to eat apples.'

b. Jabuke želim pojesti.

c. Jabuke pojesti želim.

Raising is even possible out of some finite complements:

(59) Koga ne želiš da voliš?

who not you-want that you-love

'Who don't you want to love?'

The different kinds of raising can combine freely to give examples in which a noun's pre-dependent is raised to depend on the noun's parent, whence it is further raised to depend on the latter's parent as in (60), diagrammed in Figure 7.

(60) Slatke želim pojesti jabuke.

sweet I-want eat apples

'I want to eat sweet apples.'

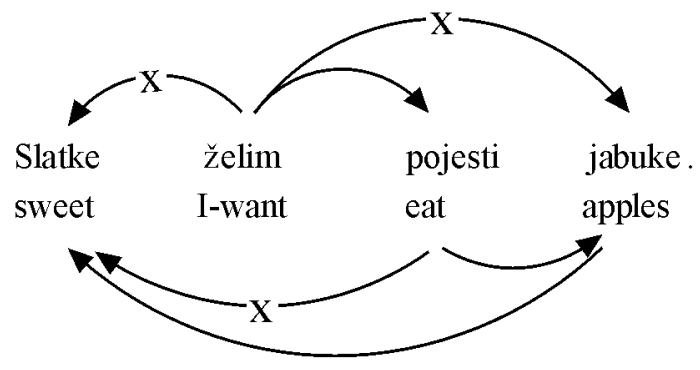

Fig. 7. Multiple raising of syntactic dependencies

In the light of this flexibility associated with auxiliary verbs, it is even more surprising to note the restriction which we illustrated in example (12), copied below: 
(60) *[Poljubio $]_{\mathrm{X}}$ jeste Ivan svoju baku.

$[\text { Kissed }]_{X}$ is Ivan his grandmother

'Ivan kissed his grandmother'

Why is it impossible for a dependent participle to stand before a non-clitic auxiliary such as jeste, when every other dependent of a verb is free either to follow it or to precede it? Suppose we explain this by stipulating that when a participle acts as the complement of an auxiliary, it is the auxiliary's post-dependent (in contrast with all other dependents of verbs which are neither pre- nor post-dependents). This immediately solves the problem of (61), which is ungrammatical because post-dependents cannot be separated from their head word by raising - i.e. its ungrammaticality has the same explanation as we gave for $(56 \mathrm{~b}, \mathrm{c})$ and $(57 \mathrm{~b})$. Of course it also raises the question of why clitic auxiliaries are so different, given that (11), repeated below, is otherwise exactly the same as (60) but is fully grammatical:

(61) $[\text { Poljubio }]_{X}$ je Ivan svoju baku.

$[\text { Kissed }]_{X}$ is Ivan his grandmother

'Ivan kissed his grandmother.'

Our answer to this question will emerge during the discussion of cliticization, where we shall also use our stipulation about auxiliary verbs and postdependents to explain why so-called 'long-head movement' is obligatory. This independent support encourages us to believe that the stipulation may be right.

The main conclusions of this section are these:

- The dependents of a non-verb have a fixed position relative to the head word, so they are classified as either pre-dependents or post-dependents.

- In contrast, the dependents of a verb are generally free to stand either before or after it, so the classification as pre- or post-dependent does not apply to them.

- Exceptionally, auxiliary verbs have participial complements which are postdependents and cannot precede the auxiliary.

- Raising allows any pre-dependent of a verb's dependent to depend on the verb as well, thereby permitting it to take its position among the verb's other dependents.

- Raising applies recursively in 'clause-union' structures, so the pre-dependent of a dependent of a verb which depends on an auxiliary-like verb may take its position from the latter. 


\section{Clitics as affixes}

We now return to our main concern, which is clitics and their relation to the hostword. Since this is a matter of morphology we shall be using the general theory of inflectional morphology described in Creider and Hudson (1999). We start therefore with a brief discussion of ordinary non-clitic inflectional morphology.

Word-types are of two kinds: lexemes and inflections. (We shall add two further kinds for clitics below.) Consequently, an inflected word inherits from some lexeme and also from at least one inflection; for example, dogs inherits from both DOG and Plural, and isn't inherits from BE as well as from Singular and Negative. These classifications mediate all the syntactic and semantic effects of morphology, so the morphological structure itself is invisible to syntax and semantics. The word (e.g. dogs) has a morphological structure (consisting of the forms $\mathrm{MdogN}$ and $\mathrm{MsN}$ ), but this is not directly relevant to syntactic or semantic rules, which treat a regular plural in exactly the same way as an irregular one such as mice.

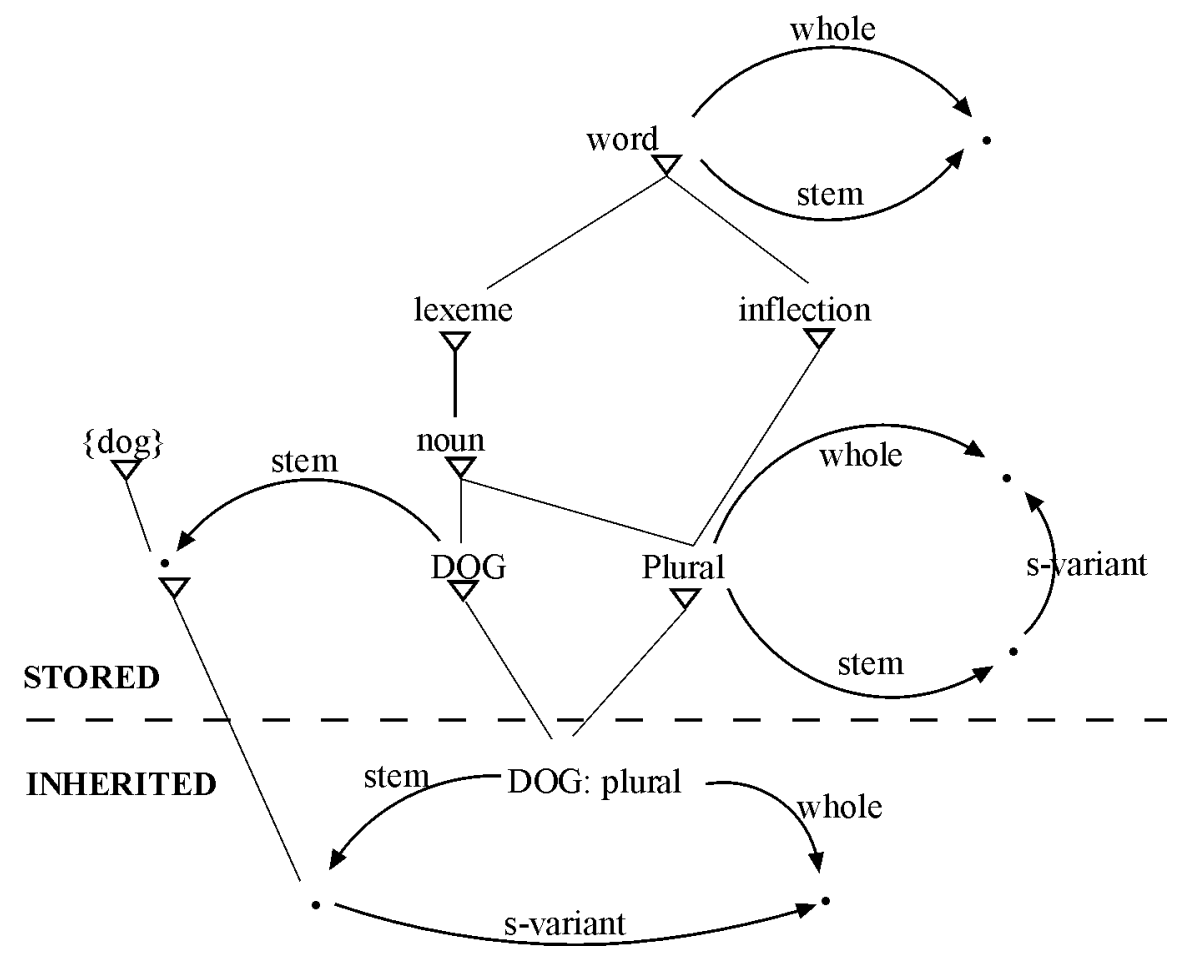

Fig. 8. The morphology of regular plural nouns in English 
A word is realised by a pattern of forms called its "whole" which is determined partly by its lexeme and partly by its inflectional classification: the lexeme contributes the stem and the inflections determine the morphological relation between this and the whole. These formal relations are 'variants' of the stem, so they are handled in terms of morphological relations such as 's-variant' (typically realised by adding MsN), 'ed-variant' and so on. Figure 8 shows how the whole and stern of 'DOG: plural' (i.e. the plural of DOG) follow from the general pattern for Plural and for DOG. Links with a small triangle show classification (e.g. DOG is a noun) and the dotted line separates the stored patterns from the pattern which can be inferred (or 'inherited', a term we shall explain below).

Perhaps the most important feature of this analysis is the clear distinction that it draws between a word and its structure. The word is an abstract object that has syntactic, semantic and contextual characteristics in addition to its observable manifestation in pronunciation or print. The observable part is not the word, but the word's structure, consisting of forms. Even when the structure is simple, it is distinct from the word - a morpheme such as MdogN, not a word such as DOG. This clear distinction allows for homonymy - two distinct words which share the same structure.

It also opens the way to a theory of clitics in which the hostword is distinct both from the clitics and from their host; in just the same way that the word DOG:plural is a distinct entity from the morphemes $\mathrm{MdogN}$ and MsN, the hostword Juče-sam-joj-ih is distinct from the forms MjučeN, MsamN, MjojN and MihN. The only difference between the two cases is that the morphemes in the second have a dual function. For example, the morpheme MjučeN is the stem of two words at the same time - of the word juče and also of the hostword; and MihN doubles up as the stem of ih and also as a suffix of the hostword. Figure 9 shows the relevant structure for this example.

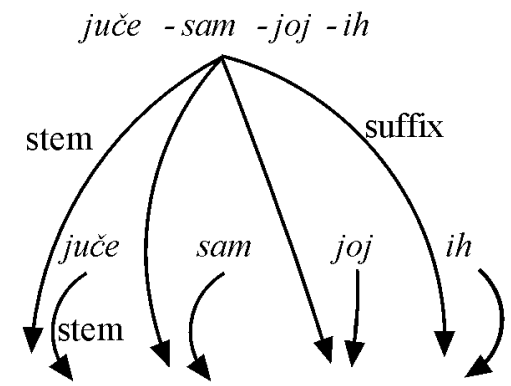

\{juče $\}\{$ sam $\}\{$ joj $\}\{$ ih $\}$

Fig. 9. Word-morpheme relations in $\mathrm{J} u \check{c}$ e-sam-joj-ih 
How does the grammar determine the order of morphemes within a word? Labels such as 'suffix' are mere labels, and need to be supplemented by explicit rules about order; and this becomes even more important when multiple suffixes co-occur in a fixed order. The same fixed order is typical of brief automatic 'scripts' - internally ordered actions such as taking a step, opening a door or changing gear - so we invoke a very general theory of wholes and parts which is not specific to language, let alone to morphology. An event (such as an uttered word) has a 'whole' which has parts that are ordered relative to each other:

- when doing such-and-such, first do this, then this, then this ...

- When taking a step, first raise a foot, then move it forward, then ...

- When saying a word, first say its stem, then say its first affix, then ...

To show the ordering of the parts we can simply assign them ascending numbers, but typically the order is independent of which parts are actually present, so the numbering reflects the maximum complexity. For example, if four suffixes are possible, the last will always be labelled "4", regardless of which other suffixes are present. In other words, we are adopting a 'templ§ate' approach to morphological structure (Stump 1998: 33).

When we apply this system to the word $\operatorname{dog} s$, we find that:

- its whole is Mdogs\};

- the first part of its whole is Mdog\}, which is also its stem;

- the second part of its whole is Ms\}, which is also its suffix.

This may seem a cumbersome way to express the trivial fact that suffixes follow stems, but it pays off in more complex cases such as SC clitic clusters. Recall the formula for clitic ordering in (2): li-aux-dat-acc-se-je (or $j e-s e)$. This can be captured by a global formula for hostwords which recognizes one slot for the stem (i.e. the word acting as host) and six numbered slots, with the last two sharing the same number:

(63) Host li-aux-dat-acc-se-je

$$
\begin{array}{lllllll}
0 & 1 & 2 & 3 & 4 & 5 & 5
\end{array}
$$

When we apply this formula to our example juče-sam-joj-ih, we find that it has the following parts:

$$
\begin{array}{lccc}
\{\text { juče }\} & \{\text { sam }\} & \{\text { joj }\} & \{\text { ih }\} \\
0 & 2 & 3 & 4
\end{array}
$$

Figure 10 shows the morphological structures for this hostword, including the word-morpheme relations shown in Figure 9. 


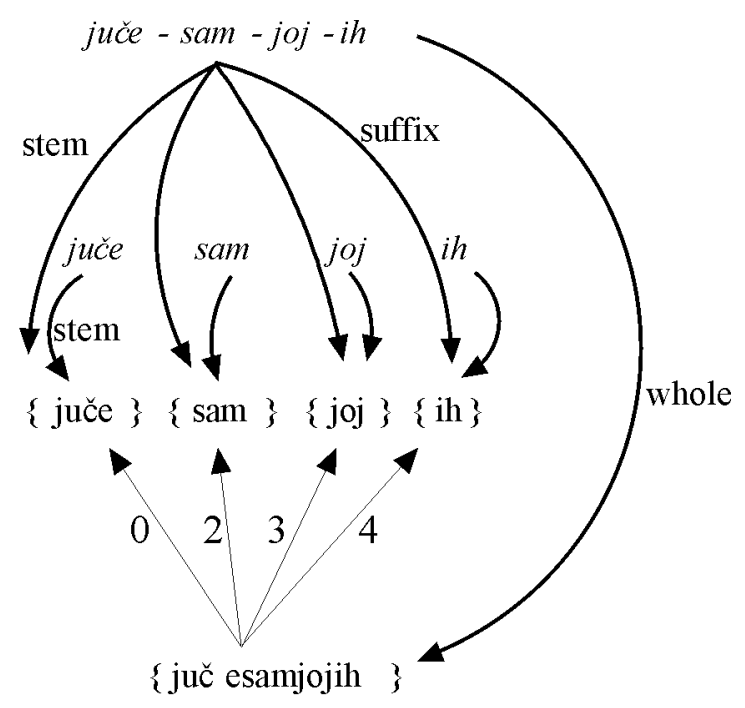

Fig. 10: The morphological structure of Juče-sam-joj-ih

One reasonable objection to this 'template' approach to morphological structure is that it merely stipulates the order of elements rather than explaining them. In contrast, it has been claimed that the order of clitics follows from the syntactic structure (e.g. Bošković 2001). Bošković argues that the ordering facts can be derived if it is assumed that clitics move to designated checking positions in functional projections. The order within the cluster, then, is a product of the syntactic ordering of the relevant functional projections. For instance, the position of the dative clitic before the accusative clitic reflects the order of agreement projections in that the indirect object AgrOP is taken to dominate the direct object AgrOP.

However, this argument fails for two reasons. First, there is no independent evidence, syntactic or other, for this particular ordering of agreement projections in syntax. It might be thought to follow from the semantic structure, but agreement projections have no semantic content (Chomsky 1995) - a fact which Chomsky uses as evidence that they do not even exist in syntax. We know of no independent syntactic evidence for this hierarchy of agreement projections. A second weakness of Bošković's explanation of clitic order is that it leaves the special position of the third person auxilary $j e$ to be explained by a phonological stipulation, a syntactic explanation being hard to imagine.

The analysis offered so far has already solved four problems:

- how to reveal the similarities between clitics and affixes: the stem of a clitic is also an affix of the hostword; 
- how to determine the order of either clitics or affixes relative to each other and to their 'host' or stem: each item is assigned a specific 'part' function relative to the larger unit;

- why modifying adjectives and determiners (but not prepositional phrases) can be separated from the rest of the noun phrase (e.g. slatki ... čaj): because pre-dependents, but not post-dependents, can be raised to take their position from the higher verb;

- why so-called 'long head movement' (i.e. an initial participle followed by the auxiliary, e.g. poljubio jeste) is not possible (unless the auxiliary is a clitic): because the participle is the auxiliary's post-dependent so its only permitted position is after the auxiliary.

The remaining problems all relate to the hostword:

- to explain why there is a hostword;

- to explain why all the clitics share the same hostword - i.e. how to explain why they cluster together;

- to explain how the hostword selects its stem, the clitics' host, including complex cases such as clitic climbing.

We can take the problems one at a time in the next section.

\section{Hostwords}

Why is there a hostword? The answer is obvious: because there are clitics. Wherever clitics occur, there must be a hostword; and without clitics, there would be no hostword. To formalize this link we recognize two additional general word types, alongside the two recognized earlier (Lexeme and Inflection). They are Clitic and Hostword.

As we have already recognized, clitics are distinguished from other words by the fact that they are realised by mere affixes, and since this is a general property shared by a number of words, we need to recognize a general category. Of course this category is not mutually exclusive with the other categories; for example clitic pronouns are pronouns (a kind of lexeme class) as well as clitics, and clitic auxiliaries are auxiliary verbs as well as clitics. This is not a problem for word grammar because it allows cross-classification by multiple inheritance. All classification is handled in terms of 'is-a' links which relate one entity (such as a word) to at least one which is more general (such as a word-class); to take our earlier example DOG: plural is-a both Noun and Plural. (As in some of our earlier diagrams, is-a links are signalled by the small triangle, whose broad base rests iconically on the super-category.) The is-a relation is fundamental because it is the basis for all generalisations: lower categories inherit all 
the properties of higher categories except for those which are overridden by exceptional features - i.e. they inherit properties by default. For example, the normal structure for Plural (i.e. a typical plural noun) is overridden by the exceptional structure of an irregular noun such as GOOSE. And of course a single entity often has more than one super-category, so it inherits from all of them.

In short, the mechanism for inheritance in WG is multiple default inheritance. This allows lexical clitics to inherit from some lexeme as well as from the general category Clitic. Normal words have a whole (i.e. their fully inflected form) which contains at least one root morpheme, but clitics inherit from Clitic the characteristic of being realised by nothing but affixes. Typically a clitic's whole is just one morpheme long, but some clitics are inflected, e.g. arguably sam consists of a root $s$ and a suffix am. Thus, a clitic's whole doubles as a mere affix in a larger wordform.

Hostwords are the reverse side of the Clitic coin, because a clitic needs a hostword. Any affix needs a "host" in the sense of a word to hold it, but most affixes are linked to specific inflections - e.g. $\{\mathrm{s}\}$ is linked to Plural or to (verbal) Singular - or lexical relations - e.g. \{er\} is linked to the "agentive" relation. This is not how clitics work; they do not realize inflectional categories or lexical relations but contribute to meaning via their syntax just like free-standing words. So clitics need a special kind of containing word which will simply give them a place in the sentence without requiring any work in return (so to speak). This is a hostword, whose main role (in terms of communication) is to hold clitics and keep them in order. It has no meaning, but, as we saw in earlier discussion, it may have syntactic dependencies of its own. Most obviously, SC hostwords have all the other clause elements as their dependents, and a constraint that they must all follow it - hence the "second position" of the clitics. In short, hostwords are words, but words with very special morphology, rather limited syntax and no semantics. This special relation between clitics and hostwords can be seen in Figure 11.

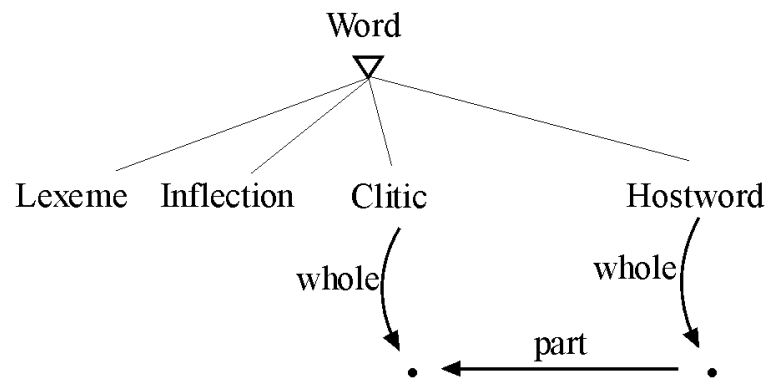

Fig. 11. The four main word-types, including Clitic and Hostword 
This, then, is why there is a hostword: because any clitic inherits (from Clitic) the need for a hostword such that the clitic's whole can act as an affix in the hostword. The next question is why clitics cluster - why all the clitics within a given clause must share the same hostword (except for the somewhat marginal cases which we discussed in 1.5 , to which we shall return in 7). The answer, of course, is that each clause offers only one 'place' for clitics - its second position - but we are now defining second position in terms of the internal structure of the hostword so this restriction does not help directly. The crucial point is that any hostword is linked to a verb and no verb allows more than one hostword; so if two clitics are linked to the same verb, they must necessarily share the same hostword.

In our example juče sam joj ih dao, the relevant verb happens to be one of the clitics (sam 'I am'), but this need not be so. The verb itself may be the host in the hostword, like dolazite in (60) (repeating (1b)):

Dolazite li često ovamo?

you-come $\underline{Q}$ often here

'Do you come here often?'

or it may be outside the hostword altogether, like dajem, 'I give', in (66):

(66) Ja mu ga dajem svaki dan. (Spencer 1991: 353)

I to-him it give every day

'I give it to him every day.'

But although the verb need not be directly involved in the cliticization, it is always relevant because it defines the domain of clitic movement: cliticization is clause-bound. In dependency terms, clitics are always located within the hostword that belongs to the verb on which they depend. In (66), both the clitics depend on dajem, 'I give', so their hostword is also linked to this verb.

What is this link between a hostword and its verb? It is not one of the familiar dependencies so we need a new name for it, so we use the term "anchor", suggesting that the hostword is "anchored" to the verb but (like an anchored boat) it still has some freedom of movement. We shall symbolize this link by the label "@", standing either for the "at" location or for the first letter of "anchor". Figure 12 shows part of the structure for two examples, one with the anchor inside the hostword and the other with it outside. (The other dependencies are labelled " $x$ " in anticipation of the discussion below where we argue that the words are all "extra" dependents of the hostword.) 

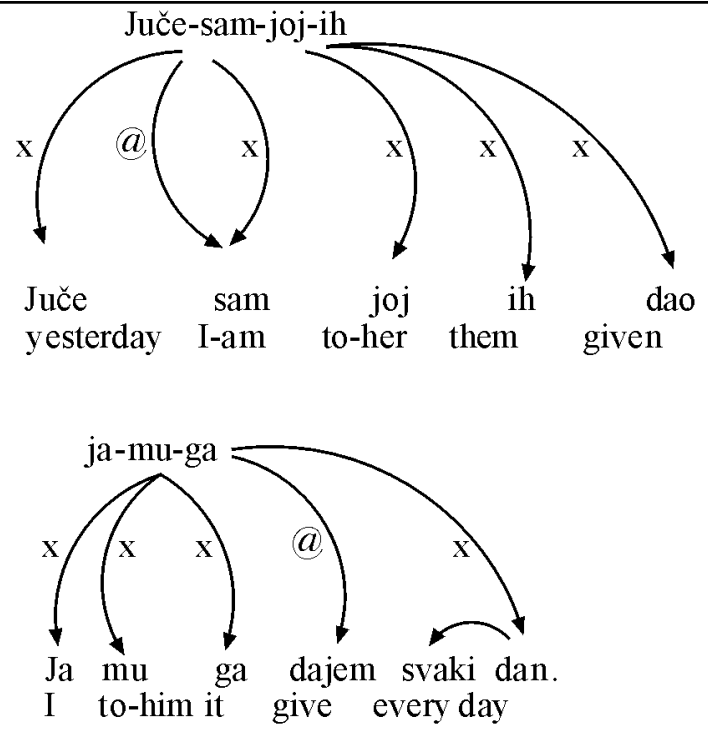

Fig. 12. Two hostwords and their anchors

The anchor verb acts as the crucial link between the hostword and its parts, so it mediates between the syntax of ordinary dependencies and the morphology of clitics.

- The anchor verb is the finite verb on which the rest of the clause depends; if the finite verb happens to be an auxiliary verb, what we called 'clauseunion' raising allows the dependents of its complement participle to depend on it as well.

- The anchor verb also licenses the hostword, rationing hostwords to one per clause.

- As we shall now explain, the anchor verb also plays an important part in deciding which word the clitics take as their host - and thereby, which word is the first part of the hostword.

How, then, is the host selected? We shall distinguish two possibilities.

The simplest case is where the anchor verb itself acts as the host - what we can call 'anchor-host identity'. An example is (1b), repeated below:

(67) Dolazite li često ovamo?

you-come $\underline{Q}$ often here

'Do you come here often?' 
In this example the finite verb dolazite is itself the host for the clitic $l i$. This case has a slight extension which is rather important in terms of the debate about SC clitics: where the anchor verb is a finite auxiliary and the host is its participial complement, as in (11) repeated below. This extension is easily motivated in functional terms as auxiliaries are prone to cliticisation so it is helpful for them to be able to take their own lexical verb as their host.

(68) Poljubio je Ivan svoju baku.

Kissed is Ivan his grandmother

'Ivan kissed his grandmother.'

Examples like this are important because they appear to involve so-called 'long head movement', but in the present analysis the movement metaphor is especially unhelpful. Poljubio is clause-initial simply because it is the first part of the hostword, and it takes this role because of its close dependency link to the hostword's anchor, the auxiliary je.

Moreover, there is no reason why this "host-absorption" should affect the position of the phrase which depends on poljubio: svoju baku, "his grandmother'. This is part of the reason why full 'VP movement' is not possible and (13) (repeated below) is ungrammatical.

(69) *Poljubio svoju baku je.

Kissed his grandmother is.

'He kissed his grandmother.'

In the present analysis, anchor-host identity is the only pattern that allows a participle to act as host, so we shall explain below why participles do not qualify for the second pattern.

The other kind of host-selection builds on examples like (24), repeated below:

(70) Veliki sivi slon spavao je pored rijeke.

Big grey elephant slept is by river

'A big grey elephant slept by the river.'

In this example the host is spavao, which is selected by anchor-host identity; but the hostword has a pre-dependent phrase veliki sivi slon, 'a big grey elephant'. As explained earlier, the pre-dependent phrase tends to be long and is often separated prosodically from the rest of the sentence, so they probably represent separate planning units. However, there is no reason to believe that this performance fact is built into the grammar. The easiest 
assumption about pre-dependents of hostwords is that they have the same freedom as other phrases either to be planned separately or to be integrated in processing with the rest of the sentence. This being so, we would not wish to distinguish syntactically between (70) and its near twin $(71)(=(25))$.

(71) Veliki sivi slon je spavao pored rijeke.

Big grey elephant is slept by river

'A big grey elephant slept by the river.'

In this sentence the host is not the verb but the last word of the pre-dependent phrase. In this particular example the last word of this phrase also happens to be its head, but examples like (7) (repeated below) show that this need not be so.

(72) Slon sa velikim uima je spavao pored rijeke.

elephant with big ears is slept by river.

'An elephant with big ears slept by the river.'

The second option for host-selection, therefore, takes as host the last word of a pre-dependent phrase; we can call this "pre-dependent absorption". In these cases it may be helpful to think in terms of topicalisation or some other kind of "fronting", or "movement", and especially so in contrast with anchor-host identity. The grammar can accommodate such examples simply by leaving the first part of the hostword unspecified. Any word will do, provided it is immediately before the clitics.

To summarise the mechanism for licensing hostwords:

- Every clitic licenses a hostword and is part of it.

- Every hostword needs an anchor, which is a finite verb.

- Every hostword also needs a first part, the "host" of the clitics that it contains.

- A word may qualify as the host in two ways:

o by anchor-host identity, either it is the anchor or the anchor is an auxiliary and it is the anchor's participial complement;

o by pre-dependent absorption, it is a dependent of the hostword which happens to stand before the hostword.

We are now ready to explain how the patterns of cliticization apply to the ordinary syntactic structures which we discussed in section 4. In that discussion we argued that SC clauses allow a great deal of raising so that pre-dependents of some subordinate words double as dependents of the words on which these depend. We introduced the term "'extra" (symbolized " $x$ ") as the name for the higher dependencies. This extra dependency 
explained the free order in examples like (60), repeated as (73), whose structure was given in Figure 5.

(73) Slatke želim pojesti jabuke.

sweet I-want eat apples

What we now suggest is that the same kind of across-the-board raising applies to the hostword, so that all the words which depend on the anchor verb also depend on the hostword - what we can call "hostword-raising" whereby every dependent of the anchor verb is also a dependent of the hostword. These extra dependencies are what cliticization needs, because they allow the hostword to relate directly not only to the words which follow it but also to the (ordinary) word round which it is built, the clitics' host. The latter pattern we shall call "host-absorption".

To see how these assumptions apply to clitics, take our stock example, juče sam joj ih dao, 'Yesterday I gave it to her.'

- The two pronouns depend (as direct and indirect object) on dao, but, by "clause-union" raising, they raise to depend on the auxiliary sam as well, so every word in the sentence depends on sam. This raising happens whether or not clitics are present.

- Each of the three clitics requires a hostword, but since this is anchored to the finite verb sam, it must be the same hostword in each case.

- By hostword-raising, every word which depends on sam also depends on the hostword. (Recall that sam itself is the hostword's anchor, a kind of dependent, so via sam every word depends on the hostword.)

- By pre-dependent absorption, the hostword absorbs one of its non-clitic dependents as its first part. In this example juče was chosen, but it could equally have been dao: Dao sam joj ih juče.

In the other example, $J a m u g a$ dajem svaki dan. 'I give it to him every day', the anchor verb is outside the hostword because it is not a clitic and the only slot available to it is already occupied by $j a$. Otherwise the structure is similar.

In summary, the hostword selects its parts via the anchor verb, of which all its parts are dependents. This is why SC clitics can split apparent phrases, such as (8) (repeated as (74)):

(74) Moj je brat poljubio svoju baku. my-nom is brother-nom kissed his grandmother 'My brother kissed his grandmother.' 
This is grammatical because $m o j$, as pre-modifier of a noun, may be raised to depend on poljubio, whence it may raise further to je, and finally to the hostword moj-je. However, similar raising is not possible for post-modifiers such as prepositional phrases.

Returning to "long head movement" and its associated problem, we now have a complete explanation. The participle alone may act as host thanks to anchor-host identity, giving examples like (68), repeated here:

(75) Poljubio je Ivan svoju baku.

Kissed is Ivan his grandmother

'Ivan kissed his grandmother.'

But neither route to host-selection allows the full "VP" to provide the host as in (69), repeated here:

(76) *Poljubio svoju baku je.

Kissed his grandmother is.

'He kissed his grandmother.'

Anchor-host identity only allows a single word, not a phrase, as host, so it does not apply here. But neither does pre-dependent absorption, because je is an auxiliary so poljubio is its post-dependent - unlike all other dependents of verbs, which are neither pre- nor post-dependents. In some languages (e.g. English) extraction can turn a post-dependent into a pre-dependent, but this option does not exist in SC so post-dependent and pre-dependent are mutually exclusive. It will be recalled that this post-dependent relation also explained the ungrammaticality of examples like (12) where the auxiliary is not a clitic; here is a simpler example which shows that any participle must follow its auxiliary, regardless of its own dependents, unless it is selected as host by anchor-host identity:

(77) a. Jeste spavala.

is slept

'She slept.'

b. *Spavala jeste.

Finally, how to explain clitic climbing? It will be recalled that clitics can 'climb' out of the complement of a verb such as "want', giving examples such as (22) and (23) where $g a$, 'him' is the object of the lower verb meaning 'see':

(78) Ivan ga je htjeo vidjeti.

Ivan him is wanted see

'Ivan wanted to see him.' 
(79) Ivan ga je htjeo da vidi.

Ivan him is wanted that sees.

'Ivan wanted to see him.'

However we also saw that ordinary clause-union raising is possible in very similar circumstances, giving examples like (58) and (59):

(80) a. Želim pojesti jabuke.

I-want eat apples

'I want to eat apples.'

b. Jabuke želim pojesti.

c. Jabuke pojesti želim.

(81) Koga ne želiš da voliš?

who not you-want that you-love

'Who don't you want to love?'

Our hypothesis is that the two phenomena are related: clitic climbing is the consequence of clause union. Thus ga and je in (78) may be in the hostword anchored to the finite verb je because they raise (by clause-union raising) to htjeo, 'wanted', whence they raise (again by clause-union raising) to je (and finally to the hostword itself).

\section{Split clusters}

We mentioned earlier (section 1.6) that some authors recognize split clitic clusters, quoting examples such as (29), repeated below, where se is separated from the other clitic, su, and // indicates an intonation break:

(82) Oni su // kao sto sam vam rekla // predstavili se Petru. they are as am you.dat said introduced self.acc Peter-dat 'They, as I told you, introduced themselves to Peter.'

The grammar of SC allows for cluster splitting under certain phonological conditions, such that the portions of the split cluster are found in two separate intonational phrases (cf. Bosković 2001). Those conditions are met in the example above since the parenthetical splits the clause into two separate phonological entities. In the absence of the parenthetical cluster splitting would be ungrammatical, as shown in (83). 
(83) *Oni su predstavili se Petru.

they are introduced self.acc Peter-dat

'They introduced themselves to Peter.'

One important condition on cluster splitting appears to be that the relative order of clitics has to be preserved. Thus, the ordering of clitic auxiliaries other than the third person form je and the reflexive se is such that the auxiliaries precede the reflexive. This ordering is preserved in (82). A sentence identical to it except that the clitics are switched is bad, as shown in (84).

(84) *Oni se // kao sto sam vam rekla // predstavili su Petru. they self.acc as am you.dat said introduced are Peter-dat 'They, as I told you, introduced themselves to Peter.'

While certain analyses of cluster splitting, such as Bosković (2001) see this pattern as fully grammatical, indeed expected under the analysis, under our proposal cluster splitting is ungrammatical but acceptable. The motivation for this claim is the fact that grammaticality judgments on these examples vary quite widely amongst speakers. Our own judgments (one of the authors is a native speaker) and those of our informants, suggest that there is a lack of clear consensus on their grammaticality.

We claim that the grammar does not, in fact, allow them; but under the pressures of performance they may be accepted as the lesser of two evils. Native speakers disagree about them because they apply different standards for acceptance: some require full grammaticality, while others ask whether they can imagine a native speaker saying the sentence. These sentences in SC are similar to English sentences like (85), where an ungrammatical pattern (a reciprocal pronoun used as subject) is accepted as the easiest way of expressing the meaning concerned:

(85) They don't know who each other invited.

Even more directly relevant is (86), where intonation rescues an otherwise ungrammatical sentence combining a present perfect tense with a definite time phrase (yesterday afternoon):

(86) I have seen him, yesterday afternoon.

In this case the time phrase is presumably added as an afterthought, so it was not anticipated when the present perfect was planned; but once the present tense has been uttered nobody but a professional grammarian would rephrase it to fit the time phrase. 
In the case of SC clitics, suppose we assume that intonation units are closely related to planning, either as the units of planning (Boomer 1965, Boomer, Laver 1968) or as 'information units' relevant to both perception and production (Halliday 2002: 270). Now consider again example (82):

(87) Oni su // kao sto sam vam rekla // predstavili se Petru. they are as am you.dat said introduced self.acc Peter-dat 'They, as I told you, introduced themselves to Peter.'

In this case the intonation boundaries reflect the speaker's planning processes, the crucial point being that at the point where the speaker was ready to utter oni su, they did not yet know that they would use the clitic se. Once the parenthesis was ready for utterance, planning resources were free-ed up again for the rest of the sentence, but by then it was too late to 'un-say' the first few words so that se could be positioned grammatically along with $s u$. The next best solution is to follow the syntax directly by attaching it (as a suffix) to its parent - hence predstavili se. This combination is acceptable given the competing constraints of on-line production and grammar, but it is not perfect - hence the uncertainty about the example's status. ${ }^{6}$ In contrast, no such explanation is possible for (84), in which the object pronoun would have had to be planned before the auxiliary.

\section{Conclusion}

Our WG analysis has solved all the main challenges of SC cliticization:

- stating the complex mutual ordering of the clitics;

- stating exactly what we mean by 'second position' (without ever referring to the notion 'clause' or any other phrase-level structure);

- ensuring that all the clitics in a clause cluster together;

- allowing clitics to 'split phrases';

- explaining the apparent complexities of 'long head movement' .

We have not tried to make the grammatical analysis account for prosodic features, but we believe our account does provide a good basis for prosodic predictions.

In contrast with the other analyses reviewed in section 2, we treat cliticization as part syntactic, part morphological. Syntactically, the clitics and their host all belong to ordinary syntactic structure, carrying ordinary dependency relations to each other and to other words. Morphologically, they are

\footnotetext{
${ }^{6}$ There are additional restrictions on cluster splitting, such as the fact that splits which separate the pronominal clitics result in a decrease of grammaticality. We do not discuss this issue here. For more detailed description of facts and one analysis of them see Bošković (2001).
} 
part of a larger word (the hostword) within which they are organized as stem and suffixes. Most of the work in the analysis is done by apparatus which is needed for ordinary syntax and morphology. Apart from the syntactic dependencies and the morphological structures needed for non-clitics, the only special theoretical apparatus that we have had to introduce for cliticization are these:

- two general word types: Clitic and Hostword;

- a special dependency type: Anchor.

Seen from this point of view, cliticization is a very simple and natural extension of ordinary grammar.

Not surprisingly, however, these simple patterns interact in complex ways. We finish with the complete structure for our main example (Figure 13), plus a bullet-point explanation.

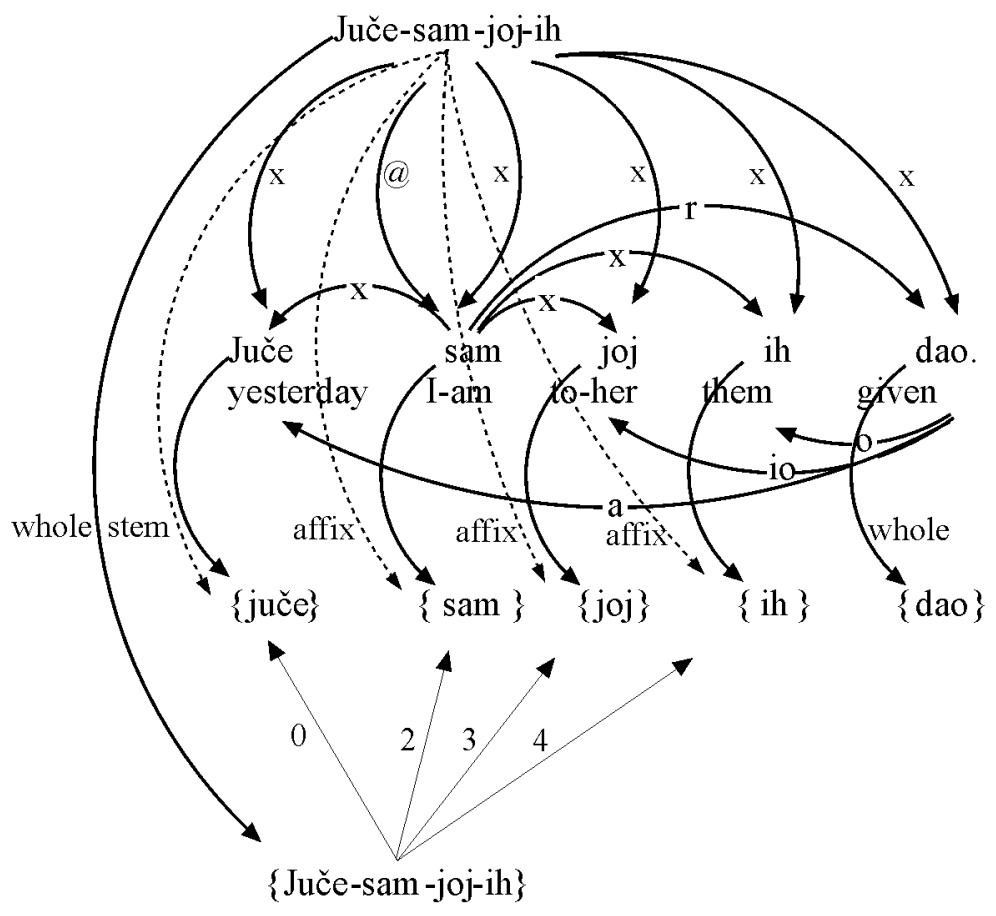

Fig. 13. The complete structure of Juče sam $\underline{\text { joj }} \underline{\text { ih dao }}$

- The words (d) are related syntactically by:

o the basic dependencies (e) - adjunct, indirect object, object - and in (c) - ' $r$ ', for 'sharer';

o the raised 'extra' dependencies in (c) whereby they depend on the finite verb sam. 
- The clitics sam, joj and ih require a hostword (a) whose anchor ('@') is the finite verb.

- All the words, including the non-clitics as well as the clitics, are "extra" dependents of the hostword (b).

- The forms $(\mathrm{g})$ are related:

o to the small words by "whole" links shown by the solid lines at (f) so that each word has a morpheme (or in the case of sam, a complex form) as its whole;

o to the hostword by stem and affix links (dotted at (f)).

- The complex form (i):

$O$ is the whole of the hostword (by the whole link at (f));

o has the wholes of all the clitics and of the host as its ordered parts (h).

This structure may look complicated, but most of the complexity is due to ordinary SC syntactic and morphological patterns. If we strip away all these links to leave only the parts which are needed strictly for the cliticization, we have Figure 14, which shows the hostword and its relations to the other words, syntactic at the top of the diagram, and morphological at the bottom.

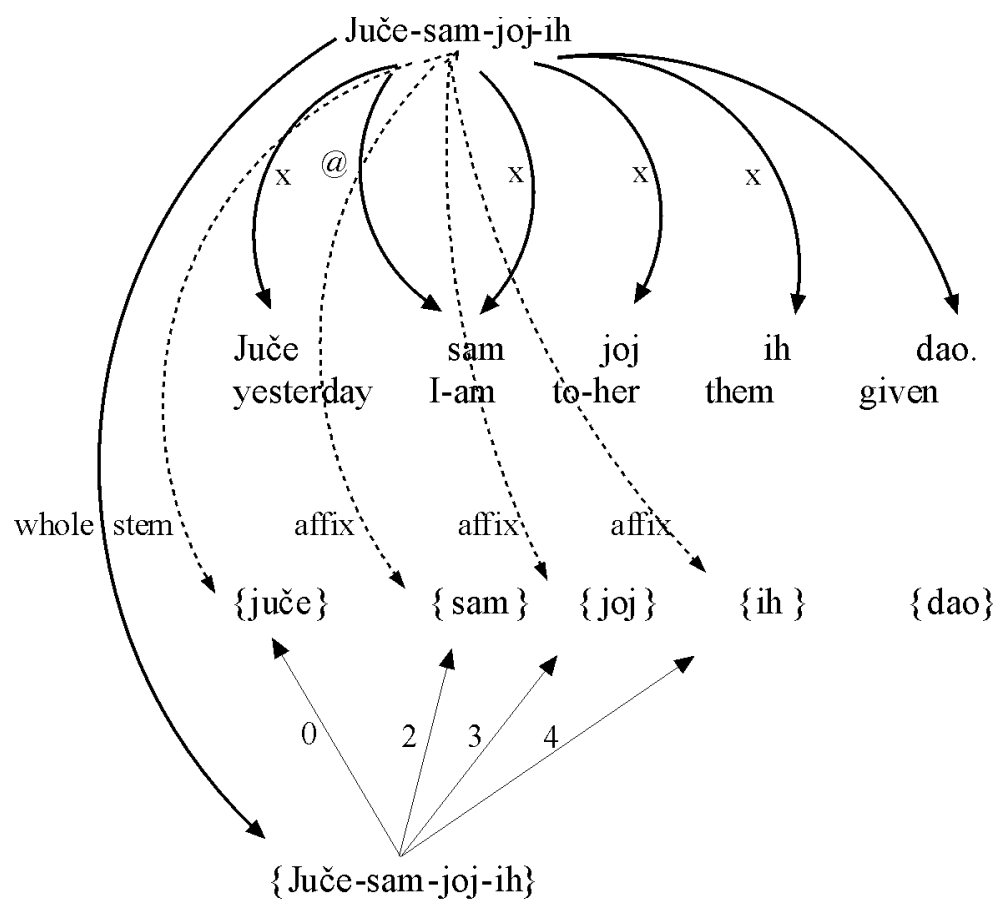

Fig. 14. The clitic structure of Juče sam joj $\underline{\text { ih }}$ dao 


\section{References}

Anders o n, S. 1993. “Wackernagel's Revenge: Clitics, Morphology and the Syntax of Second Position". Language 69, 68-98.

Anderson, S. 1996. "How to Put your Clitics in their Place or Why the Best Account of the Second Position Phenomena may be Something Like the Optimal One'. The Linguistic Review 13, 165-191.

Bennett, D. 1987. "Word Order Change in Progress: The Case of Slovene and Serbo-Croat and its relevance for Germanic',. Journal of Linguistics 23, 269-287.

B ennett, D. 2002. "Toward a better understanding of clitic systems". Proceedings of the LACUS Forum 28.

Beukema, F. and M. Dikken, (eds) 2000. Clitic Phenomena in European Languages. Amsterdam: John Benjamins.

B lake, S. J., E.-S. Kim, and K. N. Shahin (eds). 1999. Proceedings of the Seventeenth West Coast Conference on Formal Linguistics Stanford, CA: CSLI Publications.

$\mathrm{B}$ obaljik, J. 1995. Morphosyntax: The syntax of verbal inflection. PhD thesis, MIT.

B o e ckx, C. and S. Stje pan ovi ć, 2000. "The clitic/wh-connection: Evidence for Unselective attraction". In: King, T. H. and I. S e k e ri n a (eds), 22-40.

B o šk o vi ć, Z. 1995. "Participle Movement and Second Position Cliticization in Serbo-Croatian". Lingua 96, 245-266.

B ošk ović, Z. 2000. 'Second Position Cliticization : Syntax and/or Phonology?', In: B e u ke ma, F. and M. Dikken (eds) 71-119.

B ošković, Z. 2001. On the Nature of Syntax-Phonology Interface: Cliticization and Related Phenomena. Amsterdam: Elsevier.

Ca in k, A. 1998. The lexical Interface: Closed Class Items in South Slavic and English. PhD thesis, University of Durham.

Creider, C. and R. Huds on, 1999. “Inflectional Morphology in Word Grammar'. Lingua 107, 163-187.

Epstein, S. and N. Hornstein (eds). 1999. Working Minimalism. Cambridge, MA: MIT Press.

Franks, S. 1997. "South Slavic Clitic Placement is still syntactic". Penn Working Papers in Linguistics 4.2, 111-126.

Franks, S. 1998. "Clitics in Slavic". Unpublished Paper presented at the Comparative Slavic Morphosyntax Workshop, Indiana University, Bloomington.

Halpern, A. 1995. On the Placement and Morphology of Clitics Stanford, CA: CSLI Publications.

Halpern, A. and A. Zwicky (eds). 1996. Approaching Second: Second Position Clitics and Related Phenomena. Stanford, CA: CSLI Publications.

Hu d s o n, R. 1984. Word Grammar. Oxford: Blackwell.

Huds on, R. 2000. Discontinuity. Traitement Automatique des Langues 41, 15-56.

Hu d s o n, R. 2001. "Clitics in Word Grammar". UCL Working Papers in Linguistics 13, 243-294.

Hud s o n, R. 2007. Language Networks. The New Word Grammar. Oxford: Oxford University Press.

Inkelas, S. and D. Zec (eds) 1990. The Phonology-Syntax Connection. Chicago: University of Chicago Press.

J a c k e nd off, R. 2002. Foundations of Language. Brain, Meaning, Grammar, Evolution. Oxford: Oxford University Press.

Kemenade, A. and N. Vincent (eds) 1997. Parameters of Morphosyntactic Change. Cambridge: Cambridge University Press. 
King, T. H. and I. Sekerina (eds) 2000. Formal Approaches to Slavic Linguistics: the Philadelphia Meeting 1999. Ann Arbor: Michigan Slavic Publications.

Le gendre, G. 1999. "Morphological and Prosodic Alignment at Work: The Case of SouthSlavic Clitics'. In: B la ke, S. J. et al (eds), 436-50.

Nu n e s, J. 1999. "Linearization of chains and phonetic realization of chain links". In: E p s te i n S. and N. Hornstei n (eds), 217-249.

Prog o vac, L. 1996. "Clitics in Serbian/Croatian: Comp as the Second Position". In: H a 1 pern, A. and A. Zwicky (eds), 411-428.

Prog ovac, L. 2000. “Where do Clitics Cluster?'” In: B e u kema, F and M. Dikken (eds), $249-258$.

Radanović-Kocić, V. 1996. "Placement of Serbo-Croatian Clitics: A prosodic approach". In: $\mathrm{Halpern}$, A. and A. Zwicky (eds), 429-445.

Rivero, M. L. 1993. "Bulgarian and Serbo-Croatian Yes/No Questions: V0 -raising to -li versus -li hopping', Linguistic Inquiry 24, 567-575.

Rivero, M. L. 1997. "On two Locations for Complement Clitic pronouns: Serbo-Croatian, Bulgarian, Old Spanish”. In: Ke me nade, A. and N. Vi n c e n t (eds), 170-206

Roberts, I. 1992. Verbs and Diachronic Syntax. Dordrecht: Kluwer.

Roberts, I. 1994. "Second Position Effects and Agreement in COMP". Unpublished paper Presented at Formal Approaches to Slavic Linguistics 3, University of Maryland, College Park.

R o b e r t s, I. 1997. "Restructuring, head movement and locality”. Linguistic Inquiry 28, 423-460.

S a d o c k, J. 1991. Autolexical Syntax: A theory of parallel grammatical representations. Chicago: University of Chicago Press.

Schütze, C. 1994. "Serbo-Croatian Second Position Clitics Placement and the Phonology-Syntax Interface'”. MIT Working Papers in Linguistics 21, 373-473.

S pencer, A. 1991. Morphological Theory. Oxford: Blackwell.

S pencer, A. and A. Zw i cky (eds) 1998. The Handbook of Morphology. Oxford: Blackwell.

Stjepanović, S. 1998. "On the Placement of Serbo-Croatian Clitics: Evidence from VP Ellipsis". Linguistic Inquiry 29, 527-537.

S t u m p, G. 1998. "Inflection”. In: S pen cer A. and A. Zwi cky (eds), 13-43.

To mi c, O. M. 1996. "The Balkan Slavic Clausal Clitics". Natural Language and Linguistic Theory 14, 811-872.

Travis, L. 1984. Parameters and Effects of Word Order Variation. PhD thesis, MIT.

W il d e r, C. and D. C a var 1994a. "Long Head Movement? Verb Movement and Cliticization in Croatian'. Lingua 93, 1-58.

Wilder, C. and D. Cavar 1994b. "Word Order Variation, Verb Movement and Economy Principles". Studia Linguistica 48, 46-84.

Zec, D. and S. Inkelas 1990. "Prosodically Constrained Syntax". In: Inkelas S. and D. Z e c (eds), 365-378

Zwicky, A. 1977. On Clitics. Bloomington: Indiana University Linguistics Club. 